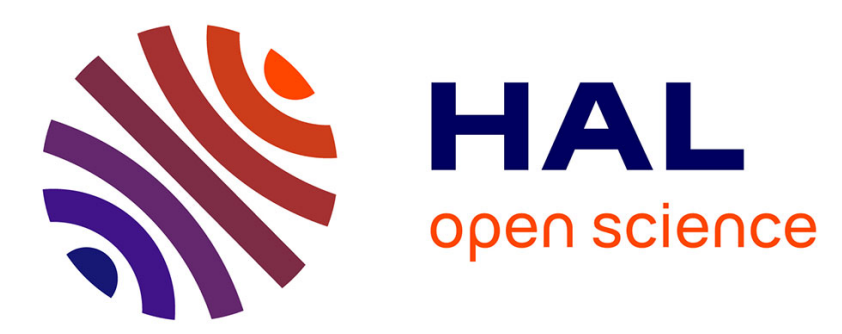

\title{
Influence of the recommendations of internet users : the role of social presence and expertise
}

Caroline Ardelet, Bérangère Brial

\section{To cite this version:}

Caroline Ardelet, Bérangère Brial. Influence of the recommendations of internet users: the role of social presence and expertise. 2012 Academy of Marketing Science Annual Conference, Academy of Marketing Science, May 2012, New Orleans, United States. hal-01264116

\section{HAL Id: hal-01264116 https://hal.science/hal-01264116}

Submitted on 1 Feb 2016

HAL is a multi-disciplinary open access archive for the deposit and dissemination of scientific research documents, whether they are published or not. The documents may come from teaching and research institutions in France or abroad, or from public or private research centers.
L'archive ouverte pluridisciplinaire HAL, est destinée au dépôt et à la diffusion de documents scientifiques de niveau recherche, publiés ou non, émanant des établissements d'enseignement et de recherche français ou étrangers, des laboratoires publics ou privés. 


\title{
Influence of the recommendations of internet users: the role of social presence and expertise
}

\author{
Caroline Ardelet \\ ATER \\ Université Paris-Dauphine \\ Dauphine Recherche en Management \\ DRM, UMR CNRS 7088 \\ Bérangère Brial \\ ATER \\ Université Paris-Dauphine \\ Dauphine Recherche en Management \\ DRM, UMR CNRS 7088
}




\section{Abstract}

The aim is to compare the influencing power of internet users' recommendations and institutional content on the internet. We show that internet users are more influential than institutional sources when they seem psychologically close. For online recommendations, social presence is a stronger lever of persuasion than expertise.

Keywords: Consumer opinion, blog, expertise, internet, social media, social presence.

The authors would like to thank Professor Christian Pinson and Professor Pierre Volle for their comments and suggestions, as well as the anonymous reviewers who, through their constructive comments, enabled us to appreciably improve this paper.

The authors may be contacted at the following email addresses:

Caroline ardelet@yahoo.fr; brial.berangere@neuf.fr

Social media currently play a key role in the product purchase decision process (Belvaux and Marteaux, 2007; Helme-Guizon, 2001; Larceneux, 2007; Kumar and Benbasat, 2006; Smith, Menon and Sivakumar, 2005). Since the advent of Web 2.0 and the emergence of a collaborative spirit, the media appear to have ascribed power and credibility to the population at large (Pisani and Piotet, 2008; Surowiecki, 2005; Tapscott and Williams, 2007) ${ }^{1}$. The content generated by internet users is presented as a better source of information than institutional content ${ }^{2}$. Even though contributing internet users have no particular expertise in evaluating the product, their opinions seem more relevant and more credible than the information emanating from institutional sources (Bickart and Schindler, 2001).

Despite the rapid development of contributory activity on the internet, academic research has yet to agree on the influence of the content generated by users compared to institutional content. On the one hand, some studies indicate that expertise is the stronger lever of persuasion (Tractinsky and Rao, 2001). Internet users would then give more credit to the recommendations of experts and brands, since they are more competent to evaluate the

\footnotetext{
${ }^{1}$ This even extends to referring to the empowerment of consumers (Firat, Dholakia and Venkatesh, 1995; Fuchs, Prandelli and Schreier, 2010), the "consommacteur" ("consumactor") (Rebillard, 2007) or the co-creation of products with consumers (Prahalad and Ramaswamy, 2004).

2 "Les 10 mythes du Web 2 .0", François Guillot, manager of Stratégies Internet du Groupe i\&e, Le Journal du Net, $23 / 01 / 2009$.
} 
product (Bounie et al. 2008; Bronner and de Hoog, 2010; Eccleston and Griseri, 2008). On the other hand, some studies suggest that the impression of psychological proximity with other internet users, who are viewed as peers, makes their opinions more persuasive (Brown and Reingen, 1987; Hass, 1981). The internet users' recommendations would then have more influence on the behavior of those internet users who consult them than the recommendations of brands, experts or journalists (Bickart and Schindler, 2001).

The present study seeks to explain these conflicts in the literature and to show, contrary to current media claims, that the content generated by internet users does not replace institutional content. To this end, we argue that the influencing power of information on the internet depends on the impression of social presence that internet users perceive. Indeed, the literature shows that internet users' trust is strengthened when they experience social presence on websites (Kumar and Benbasat, 2002a, 2002b; Gefen and Straub, 2004; Hassanein and Head, 2005, 2007). An individual approach to social presence, which takes into account the variability of individual actions with respect to information on the internet, should allow us to qualify the superiority of content generated by internet users compared to institutional content.

The paper proposes to compare the attitude toward a product, according to whether it is recommended by an internet user (user-generated content) or by a journalist in a specialized blog (institutional content), while stressing the role of social presence. We chose to focus exclusively on social presence conveyed by anthropomorphic indices (embodiment of the comment by a human being through a photograph, name and speech) (Gefen and Straub, 2003; Kumar and Benbasat, 2002a). In contrast to the comments from internet users, who are de facto personified, institutional content available on blogs may be personified, when the journalist who wrote the message is clearly identified, or impersonal, when the comments remain anonymous. We therefore provide two studies. In Study 1, we compare the opinion of an internet user - the vector of a social presence of varying degrees of strength - to a journalistic article. Since the latter is not attributed, it is assumed to be devoid of social presence. In Study 2, we complement the results obtained in Study 1 by comparing the opinion of an internet user to the opinion of a specialist journalist. Here the journalist is personally identified and is therefore assumed to convey social presence in varying degrees.

We chose to focus the research on perfume blogs, for two reasons. Firstly, since blogs are considered to be media with low social presence (Kaplan and Haenlein, 2010), they are a neutral field of study in which it is possible to manipulate the vectors of social presence. And 
secondly, perfume is a product for which other people's opinion (whether experts or not) is crucial in making a purchase decision without testing the product ${ }^{3}$.

In the first part of the paper, we define the conceptual foundations that enable us to formulate the research hypotheses. We then present the two studies, followed by the results obtained. The paper concludes with the contributions and limitations of the research, and presents future research prospects.

\section{CONCEPTUAL FOUNDATIONS AND HYPOTHESES}

\section{The influence of recommendations by experts and non-experts}

Web 2.0 has brought within the reach of internet users the tools to give their opinion on the products they consume. This new source of information thus complements institutional sources that offer information provided by brands and journalists. Several studies have shown that the recommendations of internet users have a positive effect on the behavior of their readers (Bickart and Schindler, 2001; Buhalis and Law, 2008; Chevalier and Mayzlin, 2006; Senecal and Nantel, 2004). They variously facilitate purchase (Smith, Menon and Sivakumar, 2005), arouse greater interest in the product (Bickart and Schindler, 2001; Wang et al., 2007), and increase purchase intentions (Ansari, Essegaier and Kohli, 2000; Hassanein and Head, 2005) and sales (Balagué and Florès, 2007; Clemons, Gao and Hitt, 2006; Duan et al., 2008).

While there is general agreement that the recommendations of internet users have a positive effect on the behavior of consumers who consult them, their powers of persuasion with respect to institutional content is debatable. Some authors point to the lack of expertise of internet users compared to an institutional source. They take Wilson and Sherrell's (1993) conclusion that "expertise" is the strongest lever of persuasion" and apply it to media 4 relations (Reeves and Nass, 1996). The influence of internet users' recommendations would therefore be no stronger than that of experts or brands (Bounie et al., 2008; Bronner and de Hoog, 2010; Eccleston and Griseri, 2008). But for other authors, internet users, who are viewed as peers, are more relevant and credible than the institutional information provide by brands, journalists and experts (Bickart and Schindler, 2001). The present paper aims to

\footnotetext{
${ }^{3}$ As is testified by the increasing number of internet user recommendations in dedicated forums (Osmoz.com, Beautetest.com) and general forums (Doctissimo.fr, Ciao.fr), as well as on blogs (Chroniques Olfactives, Esprit de Parfum) and online purchase sites (Sephora.fr, Yves-Rocher.fr).

${ }^{4}$ By media, Reeves and Nass understand computers, TV and the internet.
} 
clarify these differences of opinion in the literature by identifying under what conditions the power of expertise prevails over that of proximity.

\section{Social presence as a lever of persuasion}

The first definition of social presence dates back to Short, Williams and Christie in 1976. It characterized the "subjective" capacity of a medium ${ }^{5}$ to make the speaker salient in a discussion mediated by a screen (Short, Williams and Christie, 1976). It therefore refers to the capacity of the medium to restore, in the eyes of those addressed, the characteristics of faceto-face interpersonal communication (Lombard and Ditton, 1997). In the late 1990s, information systems researchers showed that social presence could be restored through social media, even though the participants did not see each other. They then identified a set of vectors of social presence, among which are anthropomorphic vectors (Appendix A2).

Short, Williams and Christie's (1976) initial definition is particularly interesting, for it makes the point that social presence is "subjective" (p. 66), i.e. that the tendency to experience presence in an internet user's opinion varies according to the individuals concerned. In particular it depends on their individual characteristics, such as gender (Gefen and Straub, 1997), their degree of acceptance of the technology (Davis, 1989; Komiak and Benbasat, 2006) or their shopping motivations (Hassanein and Head, 2005). An individual approach is therefore essential.

Short, Williams and Christie (1976, p. 72) also link social presence to another concept taken from social psychology, that of psychological distance, in Wiener and Mehrabian's (1968) sense of the term. Examination of the various definitions proposed since the 1970s (Appendix A1) shows that all authors, following Short, Williams and Christie (1976), have adopted this notion of psychological proximity under different terminologies, in speaking of "psychological presence" (Lombard and Ditton, 1997), "the capacity of the medium to convey expressiveness and emotional content" (Burke and Chindambaram, 1999, p. 566) and "understanding, connection, involvement and interaction" (Kumar and Benbasat, 2002a, p. 5). Thus social presence experienced on a blog gives internet users the impression of conversing with other internet users as if they were physically facing each other in real time (Hassanein and Head, 2007; Kumar and Benbasat, 2002a). They are unaware of the spatial and temporal

\footnotetext{
${ }^{5}$ Originally video-conferencing equipment or videophone that allows one to see remotely the person one is talking to.
} 
distance separating them. Yet while social presence reduces the spatial and temporal distance between internet users, it also diminishes social distance, i.e. social differences such as culture, upbringing, etc. Thus, when web users experience social presence, they tend to believe that other internet users are similar to themselves ${ }^{6}$. "Although the discussants in Internet forums may or may not have demographics and lifestyles that are similar to those of the reader, they are similar to readers in that they are fellow consumers" (Bickart and Schindler, 2001, p. 33).

In the physical world, when a product is recommended by someone who is viewed as similar, the person tends to think that the product matches his expectations and what he likes (Van Dolen, Dabholkar and de Ruyter, 2007). Confidence in a recommendation thus depends on the perceived similarity between the message source and the receiver (Hass, 1981; McGuire, 1969; Price, Feick and Higie, 1989). By minimizing the temporal, social and physical distance separating the receiver from the sender, social presence increases the influencing power of the recommendation. Hence a product recommendation is all the more likely to make an internet user like the product and go and find it in a store, since he feels psychologically close (spatially, temporally and socially) to the person recommending the product.

\section{Hypotheses}

In the physical world, consumers seem to give more credence to messages from people they feel close to, especially in relation to products for which preferences are heterogeneous (Feick and Higie, 1992). An in-store advisor, who is perceived as close, is more influential, even if inexperienced, than an experienced distant advisor (Woodside and Davenport, 1974). Proximity to the source is therefore a stronger lever of persuasion than expertise.

Insofar as the characteristics of face-to-face interpersonal relationships can be transferred to media relationships (Palmer, 1995; Reeves and Nass, 1996), we put forward the hypothesis that the impression of psychological proximity felt by internet users with the person making a product recommendation has a greater impact on behavior than that person's perceived degree of expertise. Thus institutional content that does not convey social presence would have no more influence on readers' behavior than content generated by an internet user.

\footnotetext{
${ }^{6}$ Internet jargon, moreover, prefers calling internet users "peers", as in the expression "peer to peer". A peer is someone of the same status, an equal.
} 
At best, its influencing power would be equivalent when the internet user reader feels close to the institutional source. We assume, therefore, that liking a product and the intention to look for it in a store should not significantly vary whether it is recommended by an internet user or by an institutional source that readers feel close to. Furthermore, if it conveys strong social presence, content generated by an internet user should have more influence on other internet users than institutional content that does not convey social presence. If, on the other hand, it does not convey social presence, it no longer has any effect on internet users' behavior. Accordingly we formulate the following hypotheses.

Hla: Compared to institutional content with weak social presence, an internet user's recommendation leads to greater liking of the product if it conveys strong social presence.

H1b: Compared to institutional content with weak social presence, an internet user's recommendation leads to a stronger intention to find the product in a store if it conveys strong social presence.

H2a: A recommendation by an internet user with weak social presence leads to the same liking for the product as institutional content with weak social presence.

H2b: A recommendation by an internet user with weak social presence leads to the same intention to find the product in a store as institutional content with weak social presence.

H3a: Institutional content with strong social presence leads to the same liking for the product as a recommendation by an internet user, whatever his level of social presence.

H3b: Institutional content with strong social presence leads to the same intention to find the product in a store as a recommendation by an internet user, whatever his level of social presence. 
STUDY 1: THE INFLUENCING POWER OF INTERNET USERS' RECOMMENDATIONS COMPARED TO IMPERSONAL INSTITUTIONAL CONTENT

\section{Research design and procedure}

The objective was to measure the attitudes of internet users toward a product according to whether it was recommended by an internet user or by a journalistic article. To this end, we chose an inter-subject design in which respondents were exposed, through an online survey, to a blog page featuring a new product. We created two versions of this page, and exposed the respondents to one or other of the versions. In the first version, the product was recommended by an internet user. In the second version, the product was described in an article written in journalistic style. The observations obtained following exposure to the internet user's recommendation were divided into two groups: on the one hand respondents who experienced strong social presence and on the other respondents experiencing low social presence. We also asked respondents, after exposure to the blog page, to evaluate on Gefen and Straub's (2004) scale (which we had translated into French), the level of social presence felt. The variable obtained after calculating a factor score roughly followed a normal distribution. To ensure that the two groups were clearly distinct, we eliminated observations lying between the 33rd and 66th percentile. We thus obtained two groups, one with respondents exposed to a recommendation perceived as having low social presence, the other with respondents exposed to a recommendation perceived as having high social presence.

\section{Creation of stimuli}

We decided to present a blog and a perfume, both of them fictional, unknown and neutral. We therefore created two versions of a product leaflet presenting the perfume Eau parfumée on the blog parfums.com (Appendices A4 and A5). For the perfume we chose a "green apple" scent ${ }^{7}$ and bottle, both in very traditional style in women's perfumery ${ }^{8}$. We made sure that the content descriptions were identical in the internet user's recommendation and in the article. The same words were used (Appendix A3). Only the sentence structure and

\footnotetext{
${ }^{7}$ According to an interview with Françoise Guermeur, Olfactory Evaluation Manager at Symrise, fruity scents are very much appreciated in France. The vocabulary around fruit odors is also more familiar and more concrete than the vocabulary associated with other olfactory families (such as amber, aromatic, woody or floral scents).

${ }^{8}$ Prior to the study, we showed the photograph of the perfume bottle in a face-to-face situation to 20 doctoral students at the University Paris-Dauphine and asked them their opinion about the bottle. The conclusion from this qualitative pre-test was that the bottle is neutral.. It arouses neither enthusiasm nor antipathy..
} 
punctuation varied, so as to be consistent with the manner of expression of the message source.

For the page with the internet user's recommendation, we used anthropomorphic and editorial vectors of social presence (Appendix A2). Thus the internet user was embodied by a woman, named Marie. This very well-known forename arouses strong approval ${ }^{9}$. She was designated by a typical Web pseudonym, Marie88, combining a name and a number, along with a photograph. A pre-test with 20 doctoral students at the University Paris-Dauphine revealed that, on the basis of this photo, Marie was perceived as a fairly attractive, likeable young woman of about thirty. In addition, the recommendation was written in an everyday spoken linguistic register (with unstructured sentences and numerous punctuation marks), as is customary in postings of this kind.

The photograph of the product was placed on the left and the text (either Marie88's recommendation or the journalistic article) on the right. To decide where to position the photo in relation to the text, we drew on research on the specialization of brain hemispheres. This research suggests that it is preferable to put the image to the left of the text rather than to the right (Ellis and Miller, 1981; Janiszewski, 1988). For when the text is located in the righthand visual field, it is more easily processed by the left hemisphere. Conversely, when the image is situated in the left visual field, it is more easily processed by the right hemisphere, the area specialized in processing visual information. This preference is corroborated by managerial practices in forums and blogs.

For the page with the journalistic article, we used a standard written linguistic register (with sentences composed of a subject, verb and possibly a complement). No information was given about the person who had written the article.

\section{The participants}

Only women were questioned, since the literature indicates that they are more attuned than men to social presence (Gefen and Straub, 1997), and 76\% of perfume purchases are made by women ${ }^{10}$. Using the snowball effect from the databases available to the researchers,

\footnotetext{
${ }^{9}$ On the prenoms.com website, the forename Marie is evaluated by 1,166 internet respondents and gets an approval rating of 4.13 out of 5 .

${ }^{10}$ Le marché des parfums, October 2007, a study carried out on behalf of Mondadori France Publicité, http://www.mondadoripub.fr/
} 
174 respondents were contacted by email and asked to participate in the online survey. Of these, 70 were exposed to member's (Marie88) contribution and 104 to the journalistic article. The procedure for eliminating individuals who experienced moderate social presence (i.e. those for whom the answers lay between the 33rd and 66th percentile) resulted in 50 responses being eliminated. In the end, this process enabled us to collect 124 observations (75 observations for the article, 22 for the low social presence recommendation and 27 for the high social presence recommendation).

\section{Measurement scales used}

\section{Social presence}

We used Gefen and Straub's (2004) one-dimensional social presence scale, which we translated into French (Appendix A6). We then calculated a factor score reflecting the impression of social presence that each respondent perceived on the web page to which she was exposed.

\section{Attitude toward the product}

We first measured emotional reactions by asking the respondents directly "Do you like the perfume that is presented on the page" and inviting them to score it on a 7-point scale. We then measured the predisposition to act in regard to the perfume through three items: Does this descriptive leaflet make you went to smell this new perfume? / If you saw this perfume in a shop, would you smell it? / If you needed to buy a perfume, would you try and find this

perfume in the shop in order to smell it? The respondents were invited to answer on 7-point scales. On the basis of these three items, we constructed a score reflecting intention behavior regarding the perfume.

\section{Control variables}

We first measured the degree of expertise attributed to the message source through a single-item scale that asked the respondents to say, on a 7-point Likert scale, the likelihood that the opinion came from someone who was a perfume expert. 
Next, the literature shows that familiarity with words facilitates their perceptualcognitive processing. The more frequently a word is used in language, the shorter is the reaction time in tests for reading aloud, lexical decision-making and lexical or semantic categorization (Allen, McNeal and Kvak, 1992; Desrochers, Paivio and Desrochers, 1989; Monsell, Doyle and Haggard, 1989; Paap and Johansen, 1994). Given that the internet user's recommendation is written in a spoken language style and the article is written in a more formal style, we took care that there was no significant difference in the ease of comprehension of the messages. Accordingly, the respondents were invited to give their opinion on a 7-point semantic differential scale. In addition, we also made sure that the cognitive effort needed to process the messages was the same. We therefore used Keller and Block's (1997) resource demand scale ${ }^{11}$.

Results

\section{Control variables}

The results show that Marie88 is viewed as less expert that the journalistic article $(\mathrm{p}<$ 0.05) (Table 1). Moreover, Marie88's recommendation is as easy to understand at the journalistic article. Differences between means are not significant $(p=0.357)$ (Table 1). The respondents consider that processing Marie88's recommendation demands as much in terms of cognitive resources as the journalistic article's recommendation. Differences between means are not significant $(\mathrm{p}=0.568)($ Table 1$)$.

(Insert Table 1)

The influencing power of internet users' recommendations compared to that of journalistic articles

The first two hypotheses postulate that, compared a journalistic article that does not convey social presence, an internet user's recommendation leads to a greater liking for the product (H1a) and to a stronger intention to find out about it (H1b), if the recommendation

\footnotetext{
${ }^{11}$ The five items of the scale were administered in the form of a 7-point Likert scale. Respondents were asked to give scores on difficulty of comprehension, the need to concentrate, whether the message was easy to understand and follow, and whether it held their attention.
} 
conveys strong social presence. We also postulated that liking the product $(\mathrm{H} 2 \mathrm{a})$ and the intention find out about it in a store $(\mathrm{H} 2 \mathrm{~b})$ do not vary significantly according on whether the product is presented in a recommendation by internet user with weak social presence or in a journalistic article.

Tests of differences between means show that there is no significant difference in liking the product and the intention to find out about it according to whether it is recommended by a journalistic article or by Marie88 $(\mathrm{p}>0.05)$ (Table 2). Thus the expertise of the source has no direct effect. However, when the product is recommended by Marie8 8 and the internet user perceives a strong social presence, liking the product and the intention to go and find it are stronger than when the product is described by the journalistic article (Figure 2). Marie88's recommendation increases the product appreciation and the intention to look for it in a store, when her opinion manifests social presence $(p<0.05)$ (Table 3$)$. Hypotheses H1a and H1b are confirmed. Moreover, when the product is recommended by Marie88 and that the internet user perceives low social presence, liking the product and the intention to look for it in a store are not significantly different from when the product is described in a journalistic article ( $\mathrm{p}>0.05)$ (Table 3). Hypotheses $\mathrm{H} 2 \mathrm{a}$ and $\mathrm{H} 2 \mathrm{~b}$ are confirmed.

\section{(Insert Figure 2)}

(Insert Tables 2 and 3)

\section{Discussion of the findings of Study 1}

Highlighting the role of social presence can reconcile apparently conflicting previous studies. The information available to internet users is not necessarily better than information provided by institutional sources. If internet contributors seem psychologically close, due to the strong impression of social presence felt in their comments, readers consider their recommendations to be more relevant and credible than those of journalistic articles. On the other hand, if internet contributors seem distant, then their recommendations have no more impact than the recommendations of journalistic articles.

$\begin{array}{llllll}\text { STUDY } & \text { 2: THE INFLUENCING POWER OF INTERNET USERS' }\end{array}$ RECOMMENDATIONS COMPARED TO PERSONAL INSTITUTIONAL CONTENT 


\section{Research design and procedure and participants}

This second study was designed to complement the results of the first study by focusing on institutional content embodied by a human being capable of conveying social presence. We again used the blog parfums.com, along with the name and perfume bottle Eau Parfumée, and compared the recommendation of an internet user to that of a journalist employed by the blog. As in the first study, respondents were exposed online, through wyzuforms software, to one of the two versions of the product leaflet we had created. In the first version, the perfume was recommended by an internet user, and in the second by an expert. The content of their two opinions was identical.

Study 2 was administered to respondents who had agreed, in Study 1, to participate in a second study on perfumes. Respondents who had been exposed to the disembodied institutional content (through the journalistic article) were exposed to the internet user opinion comments to date and those who had been exposed to the internet user's opinion (Marie88's recommendation) were exposed to embodied institutional content (an expert's opinion). All respondents subject to the same condition were thus exposed to the same processing as in Study 1 . We were aware that the first study was an initial task that could influence the results of Study 2. However, insofar as all respondents subject to the same condition participated in the same initial task, we assumed that the biases were limited.

This procedure allowed us to contact 69 respondents, 30 of whom were exposed to the internet user's opinion and 39 of them to expert's opinion. The database obtained was refined by eliminating 5 respondents whose answers revealed inconsistencies. Four of these had given the same score to more than $50 \%$ of the questions (scores of 7 for two of the respondents, and scores 1 and 2 for the other two respondents). These respondents seemed to have given scores automatically, without taking the time to consider their response. The fifth respondent eliminated had difficulty understanding the social presence scale and left a number of responses unanswered. We then adopted the same procedure as in the first study, by dividing the observations into two groups: on the one hand, respondents who experienced strong social presence and, on the other, respondents who experienced weak social presence. Since the number of observations collected was smaller than in the first study, we eliminated the responses of respondents whose factor scores lay between the 40th and 60th percentile. Accordingly we eliminated 13 responses. We thus obtained a factorial design with four 
conditions: 2 (internet user's opinion / expert's opinion) x 2 (weak experienced social presence / strong experienced social presence). We finally retained 51 responses, 20 from those exposed to the internet user's opinion and 31 from those exposed to the expert's opinion.

\section{Creation of stimuli}

We used the same blog page parfums.com and the same Eau parfumée perfume bottle (Appendices A4 and A5). We slightly altered the scent of the perfume, describing it as "a mixture of fruits". To create two versions of the product leaflet, we used the same graphics as in the product leaflets in the first study, with the product image positioned to the left of descriptive text. As in the first study, we used anthropomorphic and editorial vectors of social presence (Appendix A2). Thus the specialist and the internet user were embodied by women, named Alice ${ }^{12}$. They both expressed themselves in a day-to-day spoken register, and were represented by the same photograph which, according to a pretest with 20 doctoral students at the Paris-Dauphine University, showed them as attractive, pleasant-looking women of about thirty.

In order to clearly distinguish the internet user from the expert, we manipulated the way of presenting the identity of the contributor and the level of language used in the recommendation. Thus, the non-specialist internet user was represented by a pseudonym, Alice55, and expressed herself in everyday language, using the imperative to address the reader and numerous exclamation marks (Appendix A3). The expert, on the other hand, was presented through her first name and surname, Alice Audiart, and expressed herself in a more formal spoken register. Her position, "editor of the Perfumes page", was specified alongside her name. The use of the first and last names, and specifying an expert position in perfumery, underscored her presumed expertise.

\section{Measurement scales used}

We used the same scales as in the first study, namely Gefen and Straub's (2004) social presence scale translated into French (Appendix A6), the subjective frequency of words used,

\footnotetext{
${ }^{12}$ This very well-known name arouses strong positive feelings. One the prenoms.com website, the name Alice is rated by 750 internet users and gets a score of 4.34 out of 5 .
} 
the amount of resources needed to process the message, the perceived expertise of the source of the message, assessment of the perfume and the approach behavior score created for the first study.

Results

\section{Control variables}

The findings show that Alice Audiart is viewed as more expert than Alice55 $(\mathrm{p}<0.05)$ (Table 4). In addition, Alice Audiart's opinion is as easy to understand at that of Alice55. The differences in means are not significant $(p=0.551)$ (Table 4$)$. The respondents consider that processing Alice Audiart's opinion requires the same amount of cognitive effort as Alice55's. The differences in means are not significant $(\mathrm{p}=0.745)($ Table 4$)$.

\section{(Insert Table 4)}

The influencing power of internet users' recommendations compared to that of experts

This second study allows us to replicate the results obtained in Study 1. As in Study 1, the expertise of the message source has no direct effect on the assessment and the intention to look for the product in a store. There is no significant difference in the attitude toward the product whether it is recommended by an average internet user (Alice55) or by an expert (Alice Audiart) ( $\mathrm{p}>0.05)$ (Table 5). The effect of expertise depends on the level of social presence that the content indicates. The existing interaction between the social presence experienced and the message source is (unilaterally) significant for liking the product $(\mathrm{p}<0.1)$ and the intention of look for the product $(p<0.1)$ (Table 7). Thus the internet user's recommendation is more influential than that of the expert when the internet user's recommendation has strong social presence and the expert's has weak social presence. Under other social presence conditions, the internet user's recommendation and that expressed by the institutional source has an equivalent impact on internet users (Figure 3).

As in Study 1, difference of means tests confirm hypotheses H1a, H1b, H2a and H2b. Thus when the product is presented by Alice55 through a recommendation that carries strong social presence, it is more appreciated and intentions to look for it in a store are more 
numerous than when presented by Alice Audiart through a recommendation conveying weak social presence $(\mathrm{p}<0.05$ for liking the product and $\mathrm{p}<0.1$ for the intention of to look for it in a store) (Table 6). H1a and H1b are confirmed. Moreover, when the product is recommended by Alice55 and internet user perceives weak social presence, appreciation of the product and the intention to look for it in a store are not significantly different from the results obtained when the product is recommended by Alice Audiart and the user perceives weak social presence ( $p>0.05)$ (Table 6). H2a and $\mathrm{H} 2 \mathrm{~b}$ are confirmed.

Study 2 also aimed to test hypotheses $\mathrm{H} 3 \mathrm{a}$ and $\mathrm{H} 3 \mathrm{~b}$, which postulate that institutional content with strong social presence results in the same appreciation of the product (H3a) and the same intention to look for it (H3b) as an internet user's recommendation, whatever her level of social presence. A difference of means test shows that the expert (Alice Audiart) has as much influence as the non-expert internet user (Alice55) when the recommendation conveys strong social presence. In this instance, Alice Audiart's recommendation gives rise to the same appreciation and same intention to seek out the product as Alice55's (Table 6). H3 and $\mathrm{H} 4$ are confirmed.

\section{(Insert Figure 3)}

(Insert Table 5, 6 and 7)

\section{Discussion of the findings of Study 2}

As in Study 1, the influencing power of the recommendation does not vary significantly whether it comes from an institutional source or an internet user. The lever of persuasion lies more in the impression of social presence that emerges from the recommendation than in the source's level of expertise. Internet users' recommendations can replace institutional content only for internet user readers who feel psychologically closer to internet user contributors than to official sources. In such instances, the information provided by internet users is more relevant and credible than the information given by official sources. For internet users who feel closer to institutional sources, institutional content is as influential as the recommendations of internet users. 
Our study aimed to put into perspective the influencing power of user-generated content and institutional content on blog readers. The capacity of internet users' recommendations to induce favorable attitudes toward products presented on blogs was compared with that of (personal or impersonal) institutional sources. The focus of the paper was to understand the feeling of social presence that internet users perceive in online recommendations. This individual approach, new in the field of Media Research, produced a number of interesting results.

This research shows that, on a blog, the credence accorded to a recommendation depends on the relationship that develops between the contributor to the blog and the reader. A reader is likely to be more convinced by a recommendation when he experiences social presence in the recommendation, i.e. in terms of Short, Williams and Christie's (1976) original definition, a form of psychological proximity (social, spatial, temporal) with the internet contributor. Thus, the internet reader must feel that, through the blog, he is talking to someone similar to him, who shares the same views and who gives advice that relevant to his expectations. If so, then the recommendation generates a more favorable attitude toward the product than an impersonal institutional recommendation, such as a journalistic article, which is low in social presence. In the contrary case, the recommendation induces an attitude toward the product similar to that generated by a journalistic article. Thus the superiority of internet users' recommendations compared to institutional content proved to be the case only for blog readers who feel psychologically closer to the blog contributor than to official sources (brand, journalist or expert). All other internet users attribute much the same credence to information supplied by internet users and information supplied by institutional sources. Thus it is necessary to qualify the belief that, in social media, content generated by users, who are assumed not to be experts, takes precedence over (supposedly expert) institutional sources. Proximity to the source is a stronger lever of persuasion than expertise.

Our findings also have certain limitations that indicate the need for further complementary research. First, it is interesting to note that the social presence effect is not significant for Alice55's recommendation, but is significant for those made by Marie88 and Alice Audiart. Since neither Alice55 nor Marie88 have any great expertise regarding the product, these findings suggest the existence of another variable. The literature indicates that content generated by internet users has a greater impact on inexperienced consumers (Chen and Xie, 2008). Our respondents felt that the perfume was more similar to the perfumes they usually wear when it was recommended by Alice55 than by Marie88 and Alice Audiart ( $<<$ 
0.05). It will be interesting to see in a future study whether social presence experienced in a recommendation improves attitude toward the product less when the consumer feels herself to be an expert in the product.

Furthermore, analysis of the non-significant tendencies raises a number of questions. In Study 1, when Marie88's recommendation conveyed weak social presence, it led to a less positive attitude toward the product than a journalistic article. Institutional content with weak social presence is then more persuasive than content generated by internet users with weak social presence. Conversely, in Study 2, when Alice55's recommendation conveys weak social presence, it produces a more positive attitude toward the product than Alice Audiart's with weak social presence. Institutional content with weak social presence is then less persuasive than content generated by internet users with weak social presence. Even though these differences are too small to be significant, it seems that the effects registered may vary according to whether the institutional content emanates from a human being (a specialist or expert) or from an impersonal entity (for example, a brand). When the product is recommended by a human being, the impression of being (temporally, spatially or socially) distant might well result in a rejection of the product. This question could be addressed in a later study.

Several lines of future research may be envisaged. First, it would be interesting to study institutional content in other social media, such as an opinion leader's recommendations in a virtual community, tweets on microblogs or messages transmitted in virtual worlds, where social presence is high (Kaplan and Haenlein, 2010). Moreover, our approach involved, as is customary in internet-related research, contrasting embodied comments, taken to be vectors of high social presence, with impersonal content, which is viewed as institutional information devoid of social presence. However, although impersonal content generally includes few indices of social presence (see the list of these indices in Appendix 2), some internet users may, particularly when they know the blog very well and are attached to it, experience a form of human contact in this impersonal content. It would thus be interesting to reproduce this study on a blog conveying brand values and personality. The study should also be replicated in other areas of application, and with a sample comprising both genders. Products that are less involving and easier to verbalize, and whose benefits are more functional, could be studied. Indeed we may wonder to what extent the impression of social presence varies with the nature of the benefits that the product provides: functional, hedonic or symbolic (Park et al., 1986). Finally, although they are rarely studied in this research field, 
except for the type and level of acceptance of the technology, the variables affecting the sensitivity of internet users with different vectors of social presence (Appendix A2) or indices expected to enhance the credibility of the contributing member (e.g. contributor status ${ }^{13}$ ) need to be explored in future. Some individual characteristics of internet user readers, such as the level of self-monitoring or extraversion, may reinforce their tendency to give credence to contributions on blogs. A better understanding of these determinants in particular will help practitioners to choose their contributions moderation policy, select the most relevant indices for strengthening the impression of social presence or expertise of the contributing member, and to adopt the right balance between members' contributions and institutional content.

\section{APPENDICES}

\footnotetext{
${ }^{13}$ The system through which the contributor to a forum is successively given a different honorific status according to the number of contributions made (e.g. Gold and Silver contributor on Ciao.fr or certified buyer on Laredoute.fr.).
} 
A1 - Comparison table of definitions and measurement scales of social presence

Tableau 1 - Tableau de comparaison des définitions et des échelles de mesure de la Présence Sociale

\begin{tabular}{|c|c|c|c|}
\hline & Definition & Descristion de l'echelle & Exemples de rocheriches \\
\hline $\begin{array}{l}\text { Shorn, Williams et Chraste } \\
\text { (1976) }\end{array}$ & 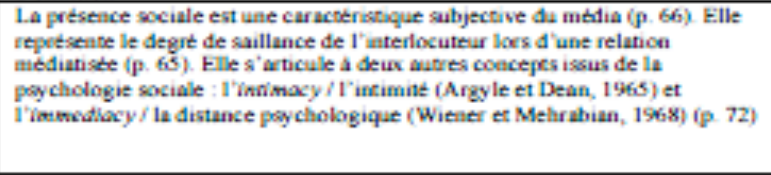 & 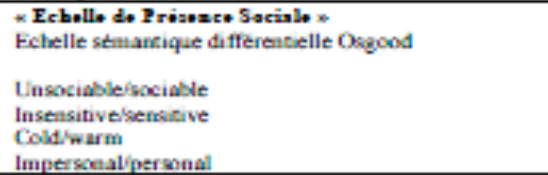 & 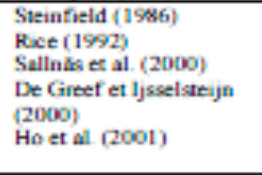 \\
\hline Gefen et Straub $(1997,2004)$ & 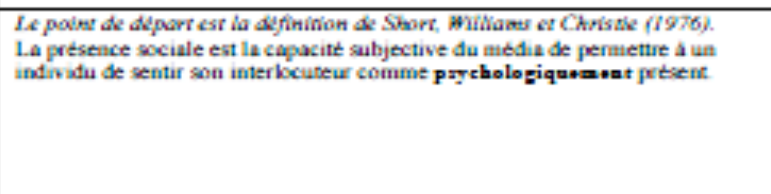 &  & $\begin{array}{l}\text { Pavlou, Liang es Xue } \\
\text { (2005) } \\
\text { Hatsanein et Head (2005, } \\
2007 \text { ) } \\
\text { Feasherman, Valacich et } \\
\text { Wells (2006) } \\
\text { Duch et Saji (2007) }\end{array}$ \\
\hline $\begin{array}{l}\text { Burke et Chodambaram } \\
\text { (1999) }\end{array}$ & 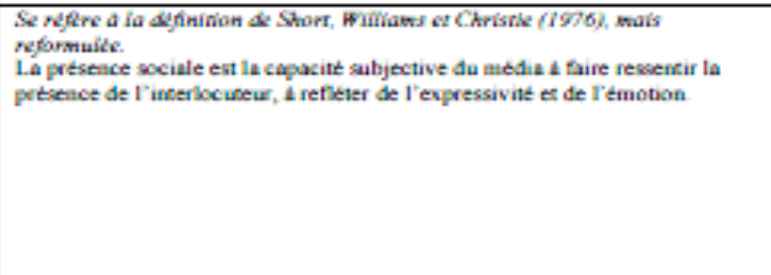 & 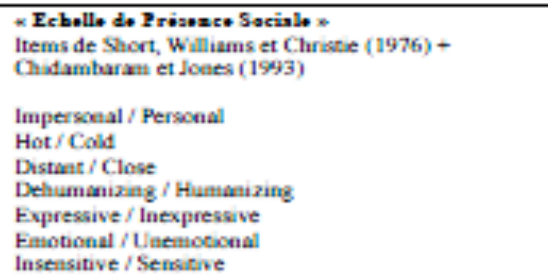 & \\
\hline $\begin{array}{l}\text { Kumar es Benbusat (2002a, } \\
\text { 2002b) }\end{array}$ & 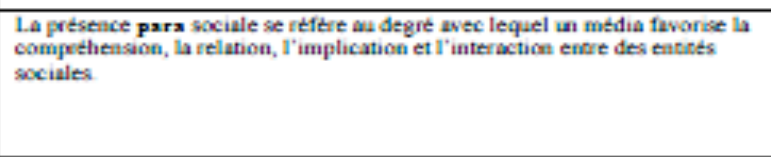 & 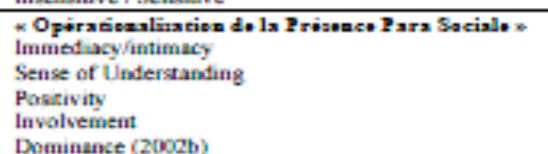 & \\
\hline Biocen et all $(2001,2003)$ & 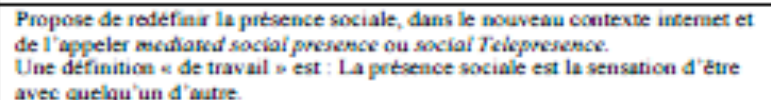 & 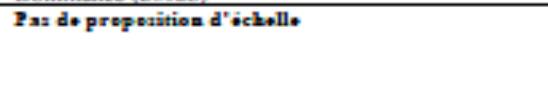 & \\
\hline $\begin{array}{l}\text { Hancanein et Head (2005, } \\
\text { 2007) }\end{array}$ & 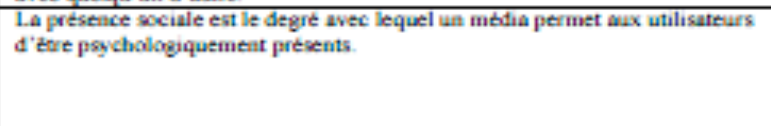 & 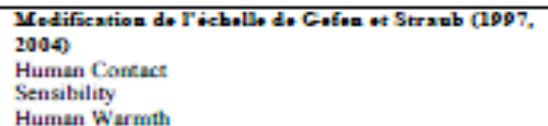 & \\
\hline Wang es al. $(2007)$ &  & 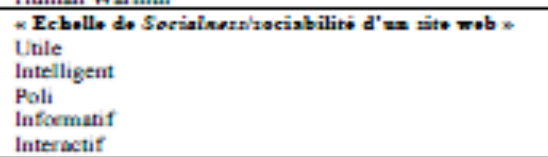 & \\
\hline $\begin{array}{l}\text { Framboch, Roest es Knishnan } \\
\text { (2007) }\end{array}$ & Unliste sans definiovol & 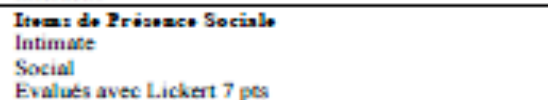 & \\
\hline
\end{tabular}


Vectors of social presence on websites

\begin{tabular}{|c|c|c|}
\hline \multicolumn{2}{|c|}{ Type of social presence vectors } & Social presence vector in detail \\
\hline \multicolumn{2}{|c|}{ Anthropomorphic vectors } & $\begin{array}{l}\text { Virtual agent (Aberg and Shahmehri, } \\
\text { 2001; Papadopoulou et al., 2001) } \\
\text { Photo, video (Gefen and Straub, 2003; } \\
\text { Kumar and Benbasat, 2002a) } \\
\text { Human voices (Lombard and Ditton, } \\
\text { 1997) }\end{array}$ \\
\hline \multirow[t]{3}{*}{$\begin{array}{l}\text { Non-anthropomorphic } \\
\text { vectors }\end{array}$} & Editorial vectors & $\begin{array}{l}\text { Text: linguistic register through lexical } \\
\text { and syntactic choices (Gefen and Straub, } \\
\text { 2003; Nass and Steuer, 1993) } \\
\text { Layout: fonts, boxes, pop-up animations, } \\
\text { colors }\end{array}$ \\
\hline & "Direct marketing" vectors & $\begin{array}{l}\text { Dispatch of emails from order to delivery } \\
\text { (Gefen and Straub, 2003; Kumar and } \\
\text { Benbasat, 2002a) } \\
\text { Greeting the customer by first and last } \\
\text { name (Gefen and Straub, 2004; Kumar and } \\
\text { Benbasat, 2002a) }\end{array}$ \\
\hline & "Web" vectors & $\begin{array}{l}\text { Consumer opinions (Kumar and Benbasat, } \\
\text { 2006), forums (Cyr et al., 2007), chat } \\
\text { (Kumar and Benbasat, 2002a), } \\
\text { Product recommendation engines } \\
\text { Web call center (chat with a salesperson) }\end{array}$ \\
\hline
\end{tabular}


Texts describing the perfume for each experimental condition

\begin{tabular}{|c|c|c|}
\hline Study 1 & Journalistic article & $\begin{array}{l}\text { Internet user's opinion } \\
\text { Marie88's contribution }\end{array}$ \\
\hline Green apple scent & $\begin{array}{l}\text { "The pleasant floral, fruity } \\
\text { fragrance opens up to the freshness } \\
\text { of a 'lime sorbet' harmonic. The } \\
\text { very light floral key reveals a note } \\
\text { of peony with a 'rosebud' } \\
\text { harmonic. In the background, the } \\
\text { woody theme is softened by musk } \\
\text { and amber notes." }\end{array}$ & $\begin{array}{l}\text { "At first, it's like a lime sorbet! } \\
\text { Then you smell the flowers } \\
\text { (peony.. or rose?!?). When you } \\
\text { wear it for a while, it becomes } \\
\text { woodier (more amber?)... In fact, } \\
\text { it's both floral and fruity! It's } \\
\text { nice." }\end{array}$ \\
\hline Study 2 & $\begin{array}{l}\text { Internet user's opinion } \\
\text { Alice55's contribution }\end{array}$ & $\begin{array}{c}\text { Expert opinion } \\
\text { Alice Audiard's contribution }\end{array}$ \\
\hline Mixed fruit scent & $\begin{array}{l}\text { The fragrance evokes a mixture of } \\
\text { acid and sweet fresh fruits. It } \\
\text { immediately reveals lemon, } \\
\text { clementine and orange, then, at its } \\
\text { heart, red fruit notes. It's a colorful } \\
\text { perfume that smells of fine days. }\end{array}$ & $\begin{array}{l}\text { "Imagine a mixture of acid and } \\
\text { sweet fresh fruits... You } \\
\text { immediately recognize lemon, } \\
\text { clementine and orange. Then you } \\
\text { also detect red fruit notes. It's } \\
\text { colorful... It smells of fine days!" }\end{array}$ \\
\hline
\end{tabular}


Blog pages presented to the internet users questioned in Study 1

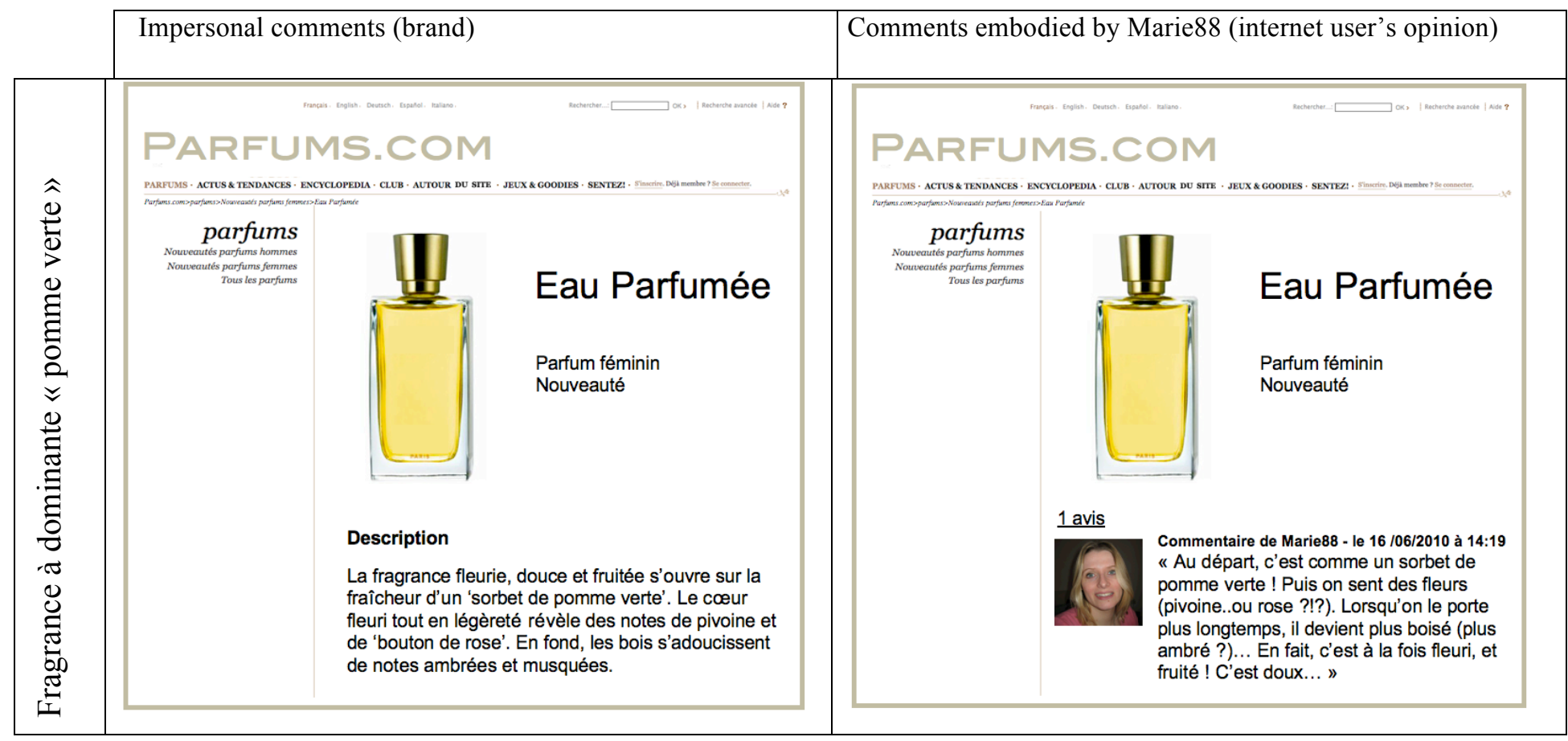


Blog pages presented to the internet users questioned in Study 2

\begin{tabular}{|l|l|l|l|l|l|}
\hline & Low expertise condition: Alice55 & High expertise condition: Alice Audiard \\
\hline
\end{tabular}


Social presence scale (Gefen and Straub, 2004)

In this page, I get the impression that ...




Table 1: Control variables (study 1)

\begin{tabular}{|c|c|c|c|c|c|c|c|}
\hline \multirow{2}{*}{ Variable } & \multirow{2}{*}{ Source } & \multirow{2}{*}{ Mean difference } & \multicolumn{2}{|c|}{ Levene Test } & \multicolumn{3}{|c|}{ T test } \\
\hline & & & $\mathrm{F}$ & Sig. & $\mathrm{t}$ & $\mathrm{df}$ & Sig. \\
\hline \multirow{2}{*}{ Easy to understand } & Impersonal institutional content & \multirow{2}{*}{0,334} & \multirow{2}{*}{0,466} & \multirow{2}{*}{0,496} & \multirow{2}{*}{$-0,924$} & \multirow{2}{*}{123} & \multirow{2}{*}{0,357} \\
\hline & Internet user's recommandation & & & & & & \\
\hline \multirow{2}{*}{ Ressource demanding } & Impersonal institutional content & \multirow{2}{*}{$-0,108$} & \multirow{2}{*}{0,277} & \multirow{2}{*}{0,600} & \multirow{2}{*}{0,572} & \multirow{2}{*}{122} & \multirow{2}{*}{0,568} \\
\hline & Internet user's recommandation & & & & & & \\
\hline \multirow{2}{*}{ Expertise } & Impersonal institutional content & \multirow{2}{*}{$-0,902$} & \multirow{2}{*}{4,573} & \multirow{2}{*}{0,034} & \multirow{2}{*}{3,125} & \multirow{2}{*}{122} & \multirow{2}{*}{0,002} \\
\hline & Internet user's recommandation & & & & & & \\
\hline
\end{tabular}

Table 2 -Source contribution and product attitude (study 1)

\begin{tabular}{|c|c|c|c|c|c|c|c|}
\hline & \multirow{2}{*}{ Source } & \multirow{2}{*}{ Mean Difference } & \multicolumn{2}{|c|}{ Levene Test } & \multicolumn{3}{|c|}{ T test } \\
\hline & & & $\mathrm{F}$ & Sig. & $\mathrm{t}$ & $\mathrm{df}$ & Sig. \\
\hline \multirow{2}{*}{ Product liking } & Impersonal institutional content & \multirow{2}{*}{$-0,346$} & \multirow{2}{*}{0,071} & \multirow{2}{*}{0,790} & \multirow{2}{*}{$-1,151$} & \multirow{2}{*}{120} & \multirow{2}{*}{0,252} \\
\hline & Internet user's recommandation & & & & & & \\
\hline \multirow{2}{*}{ Intention to buy the product } & Impersonal institutional content & \multirow{2}{*}{$-0,616$} & \multirow{2}{*}{0,056} & \multirow{2}{*}{0,814} & \multirow{2}{*}{$-1,573$} & \multirow{2}{*}{122} & \multirow{2}{*}{0,118} \\
\hline & Internet user's recommandation & & & & & & \\
\hline
\end{tabular}


Table 3- Social presence and product attitude (study 1)

\begin{tabular}{|c|c|c|c|c|}
\hline \multirow{2}{*}{ Variable } & $\begin{array}{c}\text { Social presence in internet user's } \\
\text { recommandation }\end{array}$ & Mean difference & SD & Sig. \\
\hline \multirow{2}{*}{ Product liking } & Low social presence & 0,694 & 0,367 & 0,061 \\
\cline { 2 - 5 } & Strong social presence & $-1,574$ & 0,340 & 0,000 \\
\hline \multirow{2}{*}{ Intention to buy the product } & Low social presence & 0,507 & 0,495 & 0,308 \\
\cline { 2 - 5 } & Strong social presence & $-1,530$ & 0,458 & 0,001 \\
\hline
\end{tabular}

Table 4: Control variables (study 2)

\begin{tabular}{|c|c|c|c|c|c|c|c|}
\hline \multirow{2}{*}{ Variable } & \multirow{2}{*}{ Source } & \multirow{2}{*}{ Mean difference } & \multicolumn{2}{|c|}{ Levene Test } & \multicolumn{3}{|c|}{ T test } \\
\hline & & & $\mathrm{F}$ & Sig. & $\mathrm{t}$ & $\mathrm{df}$ & Sig. \\
\hline \multirow{2}{*}{ Easy to understand } & Internet user's recommandation & \multirow{2}{*}{1,123} & \multirow{2}{*}{1,558} & \multirow{2}{*}{0,218} & \multirow{2}{*}{$-0,601$} & \multirow{2}{*}{49} & \multirow{2}{*}{0,551} \\
\hline & Personal institutional content & & & & & & \\
\hline \multirow{2}{*}{ Ressource demanding } & Internet user's recommandation & \multirow{2}{*}{$-0,090$} & \multirow{2}{*}{0,315} & \multirow{2}{*}{0,578} & \multirow{2}{*}{$-0,328$} & \multirow{2}{*}{46} & \multirow{2}{*}{0,745} \\
\hline & Personal institutional content & & & & & & \\
\hline \multirow{2}{*}{ Expertise } & Internet user's recommandation & \multirow{2}{*}{$-0,902$} & \multirow{2}{*}{0,285} & \multirow{2}{*}{0,596} & \multirow{2}{*}{$-2,364$} & \multirow{2}{*}{49} & \multirow{2}{*}{0,022} \\
\hline & Personal institutional content & & & & & & \\
\hline
\end{tabular}

Table 5- Source contribution and product attitude (study 2)

\begin{tabular}{|c|c|c|c|c|c|c|c|}
\hline & \multirow{2}{*}{ Source } & \multirow{2}{*}{ Mean Difference } & \multicolumn{2}{|c|}{ Levene Test } & \multicolumn{3}{|c|}{ T test } \\
\hline & & & $\bar{F}$ & Sig. & $\mathrm{t}$ & $\mathrm{df}$ & Sig. \\
\hline \multirow{2}{*}{ Product liking } & Internet user's recommandation & \multirow{2}{*}{0,360} & \multirow{2}{*}{0,002} & \multirow{2}{*}{0,962} & \multirow{2}{*}{0,833} & \multirow{2}{*}{49} & \multirow{2}{*}{0,409} \\
\hline & Personal institutional content & & & & & & \\
\hline \multirow{2}{*}{ Intention to buy the product } & Internet user's recommandation & \multirow{2}{*}{$-0,255$} & \multirow{2}{*}{0,249} & \multirow{2}{*}{0,620} & \multirow{2}{*}{$-0,538$} & \multirow{2}{*}{46} & \multirow{2}{*}{0,593} \\
\hline & Personal institutional content & & & & & & \\
\hline
\end{tabular}


Table 6-Social presence and product attitude (study 2)

\begin{tabular}{|c|c|c|c|c|c|}
\hline & \multicolumn{2}{|c|}{ Social presence } & \multirow[b]{2}{*}{ Mean difference } & \multirow[b]{2}{*}{$\mathrm{SD}$} & \multirow[b]{2}{*}{ Sig. } \\
\hline & $\begin{array}{l}\text { internet user's } \\
\text { recommandation }\end{array}$ & $\begin{array}{c}\text { personal institutional } \\
\text { content }\end{array}$ & & & \\
\hline \multirow{4}{*}{ Product liking } & \multirow{2}{*}{ low } & low & 1,063 & 0,610 & 0,088 \\
\hline & & strong & $-0,442$ & 0,617 & 0,478 \\
\hline & \multirow{2}{*}{ strong } & low & 1,104 & 0,538 & 0,046 \\
\hline & & strong & $-0,400$ & 0,546 & 0,467 \\
\hline \multirow{4}{*}{$\begin{array}{l}\text { Intention to buy the } \\
\text { product }\end{array}$} & \multirow{2}{*}{ low } & low & 0,688 & 0,662 & 0,304 \\
\hline & & strong & $-1,192$ & 0,669 & 0,082 \\
\hline & \multirow{2}{*}{ strong } & low & 0,979 & 0,584 & 0,100 \\
\hline & & strong & $-0,900$ & 0,592 & 0,135 \\
\hline
\end{tabular}

Table 7: Interaction effect expertise and social presence (study 2) 


\begin{tabular}{|c|c|c|c|c|c|}
\hline Product liking & & & \\
\hline Source & $\begin{array}{c}\text { Type III Sum of } \\
\text { Squares }\end{array}$ & df & Mean square & Fig \\
\hline Corrected model & 19,097 & 3 & 6,366 & 3,203 & 0,032 \\
\hline Intercept & 951,574 & 1 & 951,574 & 478,779 & 0,000 \\
\hline Social presence & 7,080 & 1 & 7,080 & 3,562 & 0,065 \\
\hline Expertise & 1,300 & 1 & 1,300 & 0,654 & 0,423 \\
\hline Erésence socialexExpertise & 6,338 & 1 & 6,338 & 3,189 & 0,081 \\
\hline Total & 93,413 & 47 & 1,988 & & \\
\hline Corrected total & 1114,000 & 51 & & & \\
\hline Corrected model & 112,510 & 50 & & & \\
\hline Intercept & & & & 3,959 & 0,013 \\
\hline Social presence & 27,774 & 3 & 9,258 & & 0,000 \\
\hline Expertise & 1220,506 & 1 & 1220,506 & 521,904 & 0,018 \\
\hline Corrected total & 13,963 & 1 & 13,963 & 5,971 & 0,812 \\
\hline Présence socialexExpertise & 7,467 & 1 & 7,467 & 3,193 & 0,080 \\
\hline
\end{tabular}


Figure 1



\section{Figure 2}

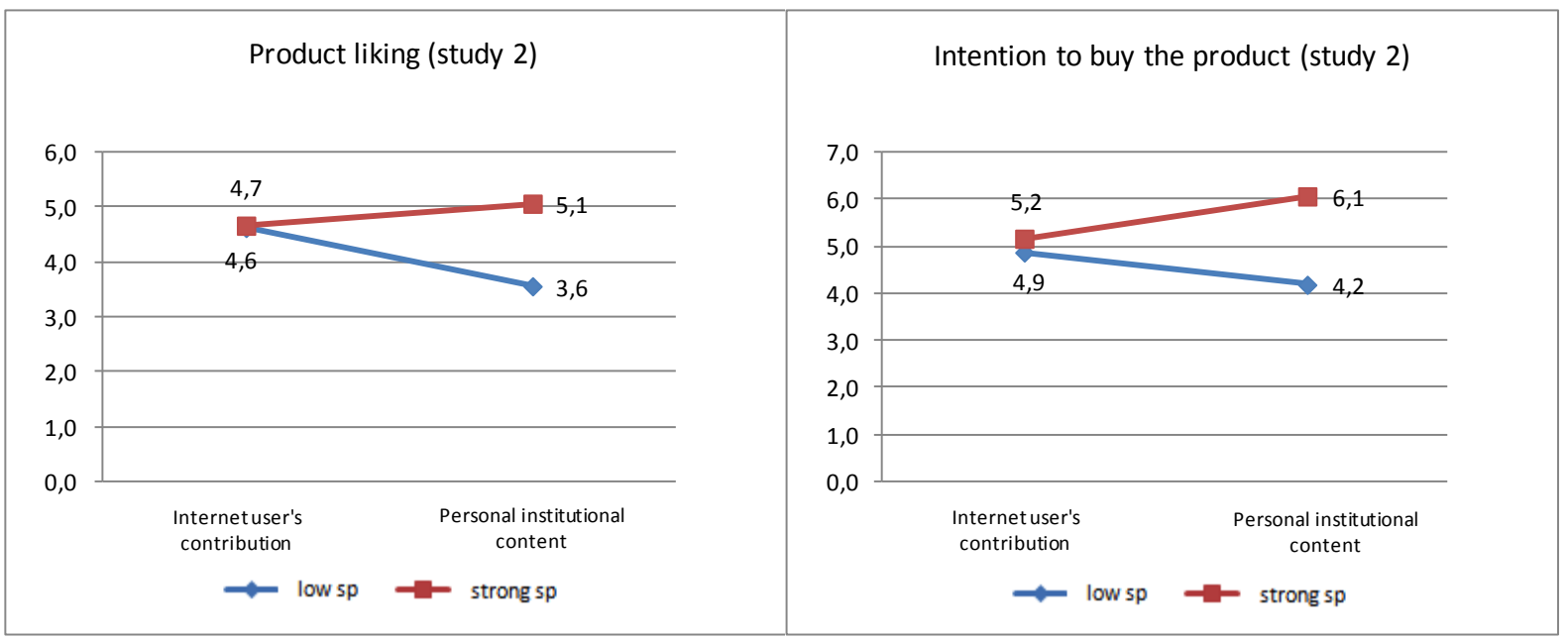


